\title{
Rain Sensor with Stacked Light Waveguide Having Tilted Air Gap
}

\author{
Kyoo Nam Choi \\ Department of Information and Telecommunication Engineering, Incheon National University, Incheon 406-772, Republic of Korea \\ Correspondence should be addressed to Kyoo Nam Choi; knchoi@incheon.ac.kr
}

Received 1 April 2014; Revised 4 June 2014; Accepted 5 June 2014; Published 26 June 2014

Academic Editor: Marco Consales

Copyright (C) 2014 Kyoo Nam Choi. This is an open access article distributed under the Creative Commons Attribution License, which permits unrestricted use, distribution, and reproduction in any medium, provided the original work is properly cited.

\begin{abstract}
Vehicle sensor to detect rain drop on and above waveguide utilizing light deflection and scattering was realized, keeping wide sensing coverage and sensitivity to detect mist accumulation. Proposed sensor structure under stacked light wave guide consisted of light blocking fixture surrounding photodetector and adjacent light source. Tilted air gap between stacked light waveguide and light blocking fixture played major role to increase sensitivity and to enhance linearity. This sensor structure eliminated complex collimating optics, while keeping wide sensing coverage using simple geometry. Detection algorithm based on time-to-intensity transformation process was used to convert raining intensity into countable raining process. Experimental result inside simulated rain chamber showed distinct different response between light rain and normal rain. Application as automobile rain sensor is expected.
\end{abstract}

\section{Introduction}

Currently the portion by electronics in automobile has continuously increasing tendency, and the rain sensor is one of such electronic components in vehicle. Rain sensor in vehicle is used to actuate wiper automatically in case it senses rain on and above windshield glass. Numerous ideas and concepts regarding windshield rain sensor have been proposed, such as mechanical [1], acoustic [2], resistive [3-7], capacitive [816], optical imaging [17-26], microwave [27, 28], and optical [29-36] rain sensors; however, problems relating such as linearity, sensitivity, disturbance, malfunction, sensing area, and structural complexity limited their application to vehicle. This was due to the random nature of raining which is inherent to liquid. However, it is required to have adequate linearity in raining intensity for the range where driver wants to distinguish to wipe the windshield for driving convenience. Among conventional concepts regarding rain sensor, the mechanical sensor monitored the variation in vibration amplitude and frequency by rain drops, and the acoustic method monitored sounds by rain drop using electret microphone. The resistive method measured DC resistance between the dot [3] or linear $[4,5]$ or interdigitated $[6,7]$ electrodes; however, these electrodes were located outside windshield glass which were subject to abrasion and dust accumulation. The capacitive detection method monitored the variation in capacitance between the electrodes inside windshield glass, and this capacitance change by rain drops was converted to impedance change [13] in capacitance bridge or frequency change [14-16] in LC resonance circuit. In this method, if the interdigitated finger patterns were once wet, then it was not able to sense the next rain drop, and it resulted in shifting the linear region to weaker raining intensity rather than practically usable intensity. Optical imaging method, using imaging array sensor [17-24] or camera [25, 26], had the advantage of sensing wider area using simple optical component; however, it was inherently susceptible to rushing scenery while driving. The other microwave radar detection method was attempted by simulating scattering between microwave and rain interaction. Optoelectronic detection method has been commonly used to detect the presence of rain drops on windshield glass, because optically transparent nature of windshield glass, within limited optical spectrum, linked optical signal path between sensor located inside glass and rain drops located outside glass. Rain sensing method using direct attachment of light source and photodetector 
inside windshield glass $[29,30]$, in between barrier is placed to suppress primary parasitic radiation, was proposed; however, this configuration had limitation to increase sensitivity due to unwanted secondary parasitic radiation otherwise had low sensitivity. Two optoelectronic types, distinguishing by optical paths, have been widely used in vehicle. Reflection type sensor utilized reflected light by rain drop on the surface of windshield glass by using camera [31] or inclined sensor attachment plane [32] or light beam [33, 34]. Among these, the method using collimated light beam [34] from light source was strong enough to reject ambient light effect while reaching to photodetector; however, it formed only a small detection spot on windshield glass surface resulting in insufficient sensing area and linearity to discriminate raining intensity. To compensate this deficiency, the configuration having multiple optical paths was proposed [35] and used in the automobile. The most notable optical sensing scheme was optical waveguide type sensor [36], in which the collimated infrared light beam was coupled into windshield glass panel by using prism coupling method. In this scheme, a line of channel between light source and photodiode formed rain sensing lane, and the amount of leaked light by rain drops was monitored. This method had limited sensing area but had sensitive response to the presence of raindrop with reduced interference by ambient light. However, it was also susceptible to the shock and vibration imposed to the light coupling interface and required complex optical components. Most optical rain sensors require a rigid mounting apparatus [37-39]. Scattered light detection method is an alternative to the previous arts, which can not only eliminate complex optical fixture but also extend detection area in 3 -dimensional spaces. The trade-off to these advantages is weak light response to raindrop. Therefore, there is a need for rain sensor having wide sensing coverage and enhanced sensitivity without complex optical components. This paper is about a sensitive rain sensing method using both scattered and deflected light detection without complicated optical collimation fixture.

\section{Rain Detection Theory}

2.1. Scattered Light Sensing. Conventional optoelectronic rain sensing method used collimated light beam to minimize optical power loss from infrared light source. Two kinds of rain sensing structures have been used. The concept of reflection type rain sensor, which detects the degree of light leaking on reflecting spot using collimating optical fixture beneath windshield glass, is shown in Figure 1(a). And the concept of optical waveguide type rain sensor utilizing light channel formed inside windshield glass connecting between light source and photodetector is shown in Figure 1(b). Vehicle rain sensor, utilizing scattered light, places light source and photodetector underneath windshield glass. Light shield is essential to block directly transmitted light from light source. In this case, transmitted light is reflected at the interface of two transparent materials, if the refractive indices are different. And the reflected optical power is proportionally related to index difference. The concept of rain

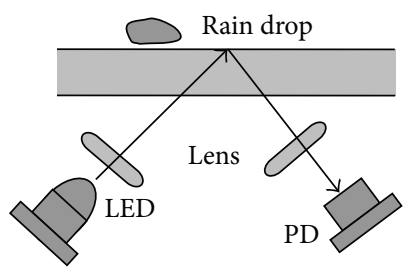

(a)

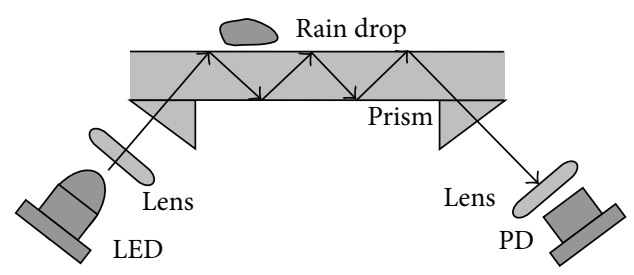

(b)

FIGURE 1: Optical rain sensors: (a) reflection type and (b) waveguide type.

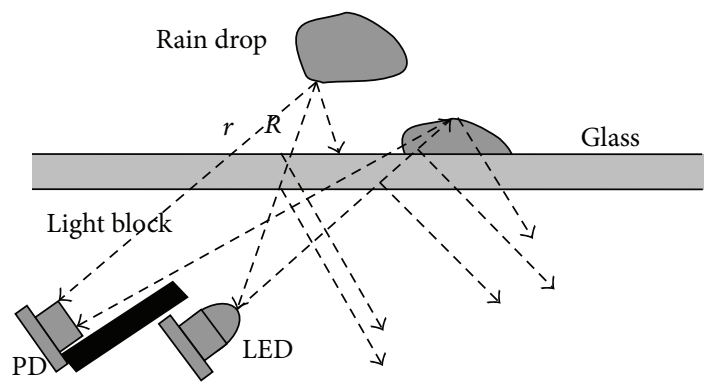

FIGURE 2: Concept of rain sensor using scattered light detection.

sensor using scattered light detection is shown in Figure 2. Actual light paths are various rather than the typical one shown in Figure 2. The scattered light by rain drops which are close to windshield glass is the major signal source for detection. It is necessary to avoid direct light emission and reflection other than by rain drops on or above windshield glass to avoid interference by stray light.

Transmitted light from light source travels the distance " $R$ " to rain drop. And it reflects back to photodiode after traveling the distance " $r$." The received light optical power at photodetector location can be expressed as shown in (1) [40], and this received power has relationship with the rain drop morphology and the distance between rain drop and LED. In (1), $\Phi(r, \theta, \phi, t)$ is morphology of rain drop, $S_{\mathrm{PD}}$ is photosensitive area of photodetector, $P_{i}(t)$ is received intensity, $P_{o}(t)$ is emitted intensity, $P_{R 1}(t)$ is reflection probability by rain drop, and $P_{R 2}(t)$ is signal reception probability at photodetector:

$$
\begin{gathered}
P_{i}(t)=P_{o}(t) \cdot P_{R 1}(t) \cdot P_{R 2}(t), \\
P_{R 1}(t)=\frac{\pi r^{2}}{\left(4 \pi R_{1}^{2}\right)} \cdot \Phi_{R 1}(r, \theta, \phi, t), \\
P_{R 2}(t)=\frac{S_{\mathrm{PD}}}{\left(4 \pi R_{2}^{2}\right)} \cdot P_{R 1}(t) .
\end{gathered}
$$




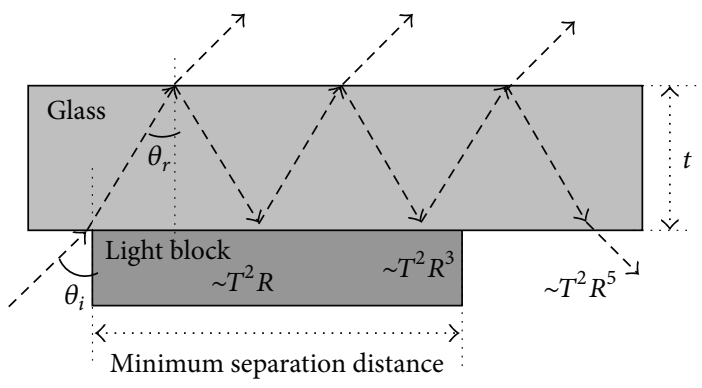

(a)

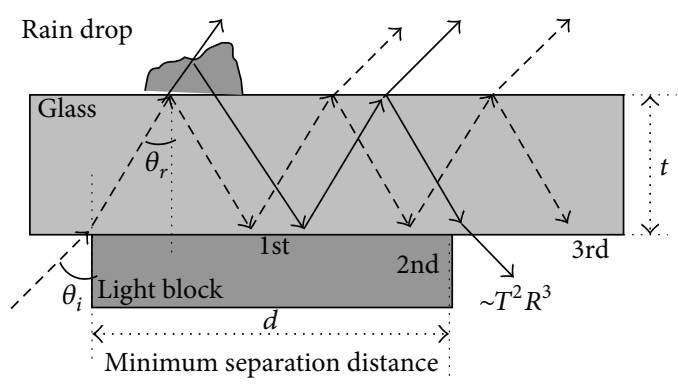

(b)

FIGURE 3: Concept of rain sensor using deflected light detection: (a) without rain drop and (b) with rain drop.

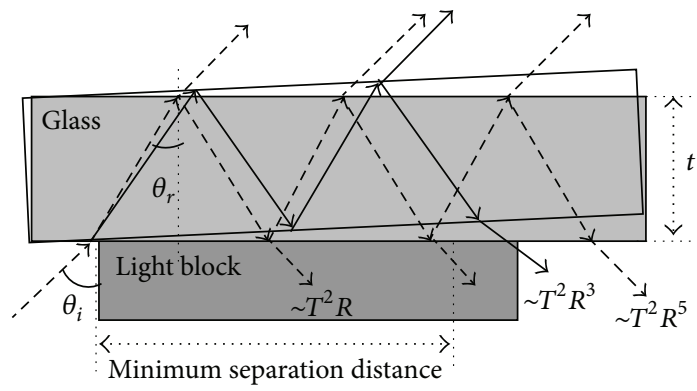

(a)

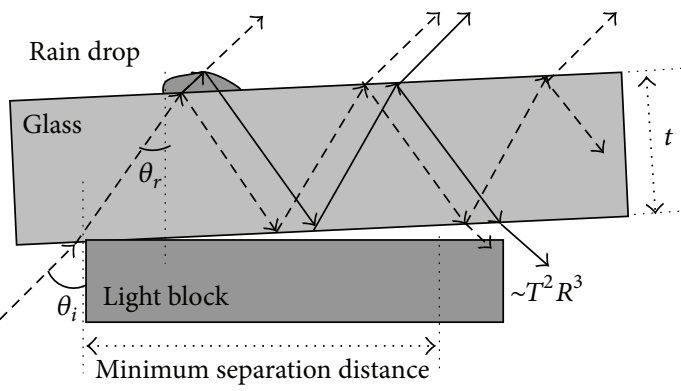

(b)

FIGURE 4: Concept of rain sensor using deflected light detection method with tilted air gap: (a) effect of tilted air gap and (b) effect of rain drop with tilted air gap.

2.2. Deflected Light Sensing. If the collimated light is incident into glass medium, light is transmitted following transmission rate $T$ and reflected following reflection rate $R$ at interface surface of two transparent materials having different refractive indices. For instance, transmission rate is around $96 \%$ and reflection rate is around $4 \%$ at interface surface between air and glass medium depending on incident angle and exact value of refractive indices. If light block, which rejects direct transmission from light source to photodiode, is placed to allow only signals after third reflection on top glass surface as shown in Figure 3(a), then the signals after second reflection can reach the photodetector because a rain drop on glass surface causes an increase in glass thickness, resulting in altered light path as shown in Figure 3(b).

The difference in light intensity between second and third reflections is around $R^{2}$ which is equivalent to $1.6 \times 10^{-4}$ as shown in Figure 3. Thus, intensity difference shows almost discrete step and is suitable to set threshold point to determine whether rain is dropping or not. In case the incident light is not a collimated light, intensity difference between second and third reflections is close to discrete step due to the presence of light block fixture, although the difference becomes less than the case for collimated incident light. If the minimum separation distance, $d$, in Figure 3 approaches to the point barely after second reflection, then the probability of detecting rain drop will be maximized. However, this method is expensive to realize, because it requires maintaining high precision level in fixture dimension.
2.3. Deflected Light Sensing with Tilted Air Gap. Instead of maintaining high precision level in dimension to accurately adjust minimum separation distance by using light blocking fixture, placing tilted air gap between windshield glass and light blocking fixture is a convenient way of continuously adjusting threshold point to maximize rain detection sensitivity.

When the tilted air gap is not present, the second reflected light by upper glass surface is blocked by light blocking fixture. In this state, the small rain drop will not be sufficient to deflect light path of above the second reflected light out of light blocking fixture. When the tilted air gap is present, the second reflected light by upper glass surface is barely blocked by light blocking fixture as shown in Figure 4(a). In this state, only small rain drop will be sufficient enough to deflect light path out of light blocking fixture and reach into the aperture of photodetector as is illustrated in Figure 4(b). By adjusting tilt angle between glass waveguide and light blocking fixture, the light deflection can be continuously adjusted by adjusting tilting angle between windshield glass and light blocking fixture, resulting in high sensitivity. The effect of tilting angle to the degree of deflection can be explained as shown in Figure 5. In case when light is incident to the bottom surface of windshield glass with incident angle $\theta_{i}$, then this light will be transmitted through bottom surface and again incident to top surface of windshield glass with incident angle $\theta_{r}$. If we set the tilting angle as $\theta_{t}$, then the reflection angle will be $\theta_{r}+2 \theta_{t}$. This deflection shifts light path as $t \cdot\left(\tan \left(\theta_{r}+2 \theta_{t}\right)-\tan \left(\theta_{r}\right)\right)$ 


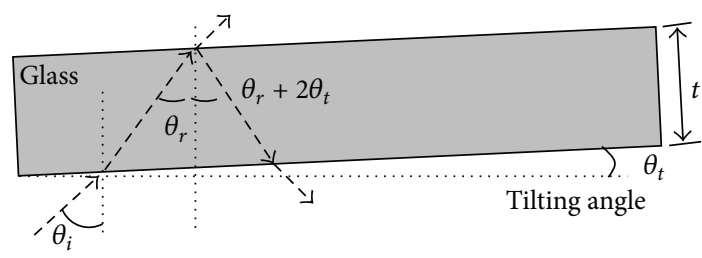

FIGURE 5: Effect of tilting angle to light path shifting.

in horizontal direction, if we assume tilting angle is small usually less than a few degrees.

2.4. Raining Intensity Quantization. It is important to determine the intensity of raining to control wiper actuating interval in automobile. However, the signal response by light scattering process [41-44] has random stochastic characteristics; thus, it is hard to configure linearly in relation to raining intensity. Thus, it is necessary to quantize the raining intensity by transforming scattering process. Direct quantization of analog value is not feasible, because sensor output is digital value. Thus the algorithm, converting digital value of raining intensity to analog value, is necessary to utilize in rain sensor. The frequency of rain detection in predetermined time interval is used to determine raining intensity. And the figure indicating the degree of continuous rain detection is used to determine rain drop size. One time frame, which is predetermined time interval, is divided into multiple time slots, and each time slot represents rain detection event; thus, it forms time-to-intensity transformation. Through this transformation, the probability of raining is determined by counting active time slots in predetermined time interval. The structure of one time frame having multiple time slots is illustrated in Figure 6. In the case of drizzling rain, only one time slot represents active slot; however, more slots will be active in more raining condition. In an extreme case as shower, all time slots will be active. We can extract the data for raining intensity and rain drop size by analyzing active time slot pattern in one frame time.

In time-to-intensity transformation, the raining probability, $P(t)$, in one frame time is evaluated by combining the probability for size of rain drop and the probability for raining time as shown in (2), where $N$ represents the time slot number, $A_{i}$ represents the weighing factor of rain drop size, $B$ represents the weighing factor to active time slots, $S(t)$ represents continuous slot times, and $n_{\mathrm{ts}}(t)$ represents the number of time slots detecting rain drop:

$$
P(t)=\sum_{i=1}^{N} A_{i} S_{i}(t)+B \cdot \frac{n_{\mathrm{ts}}(t)}{N} .
$$

Thus, this time-to-intensity transformation process utilizes data for rain drop size, $A$ code, and raining time, $B$ code, to determine wiper actuating interval. In the case of shower raining, $A$ code sends signal to actuate with high speed, and $B$ code sends signal to actuate windshield wiper. In case of light raining, $A$ code sends signal to actuate with low speed, and $B$ code sends signal to actuate windshield wiper. While

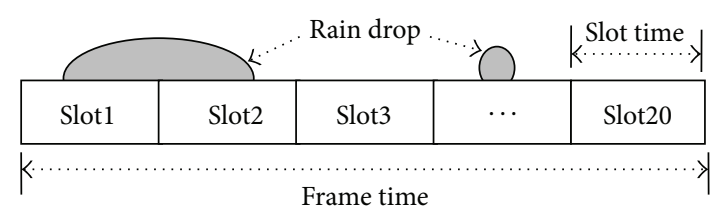

FIGURE 6: Frame time and slot time in time-to-intensity transformation.

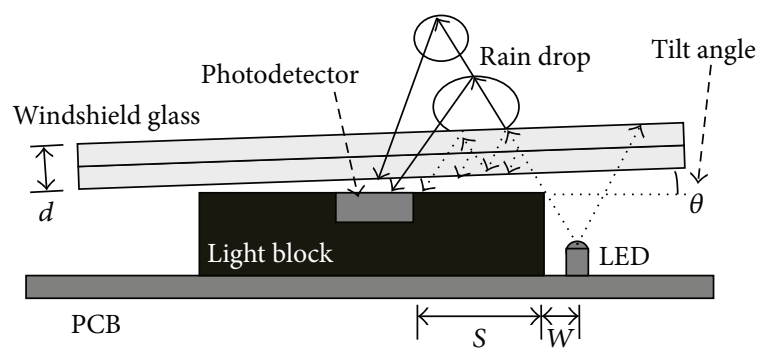

FIgURE 7: Rain sensor structure.

only with mist condition, $B$ code only sends signal to actuate wiper motor when the rain drop is detected.

\section{Experiment}

3.1. Rain Sensor Structure. The windshield glass of automobile has the laminated glass structure in which thin polyvinyl butyral resin film is inserted as impact absorber. The refractive index of above resin film is in the range between 1.6 and 1.8, which is close to refractive index of glass, and the thickness of film is negligible in comparison to glass thickness. The rain sensor was fabricated using commercial windshield glass having 2 stacked light waveguides, $2 \mathrm{~mm}$ thickness each, as shown in Figure 7. The tilt angle of windshield glass was adjusted so that the second reflection from top glass surface is barely blocked by light blocking fixture. In case rain drop is present on or above the top glass surface, then new deflected light path is created by reflection on rain drop surface. This deflection causes reduced reflection step, resulting in order of magnitude higher optical power input to photodetector than the state without rain drop.

The deflected light path outside windshield glass is the primary signal source for wiper actuation. The photodetector senses two signal paths, reflected light by rain drop on windshield glass and scattered light by falling rain drop. The reflected optical power from the rain drop on windshield glass is adjusted close to scattered optical power by falling rain drop above windshield glass, by keeping adequate distance $S$ to equalize signal intensity by rain drops. The incident angle from light source is controlled by adjusting the distance $W$ between light block and light source. Directly propagating light from light source was blocked by light blocking fixture before reaching to photodetector as shown in Figure 8. Signal amplification rate for deflected and scattered lights was limited by the amount of stray light even while recessing photodetector inside light block. 


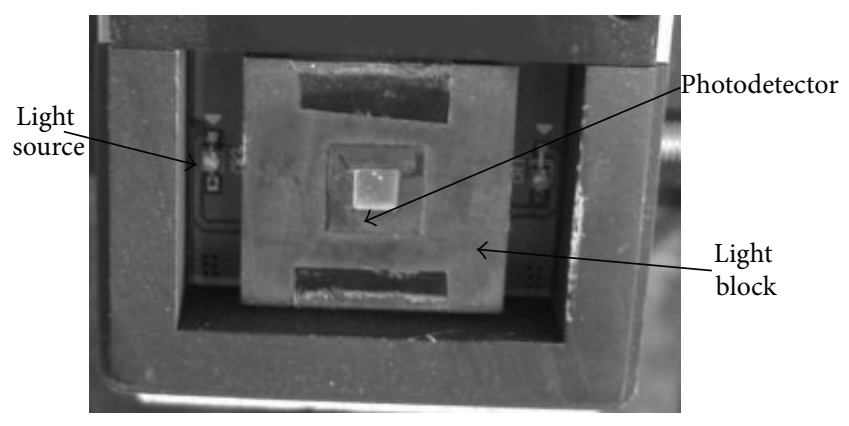

Figure 8: Top view of fabricated rain sensor.

3.2. Signal Processing. The emission angle of light source is critical for rain detection. The wide angle provides wider detection area, while the narrow angle expands detection resolution within limited detection coverage. The LED with flat top window having half power angle of 90 degree was chosen to expand detectable area. The higher periodic instantaneous drive current of $60 \mathrm{~mA}$ was injected to LED by keeping $25 \%$ of duty cycle ratio to prevent overheating, in comparison to normal continuous drive current of $20 \mathrm{~mA}$. The light modulation frequency was chosen to $73 \mathrm{kHz}$ to reject unwanted ambient light effect. The higher frequency is advantageous to increase detection probability because of higher sampling rate; however, from practical view point, this also increases chance for oscillation due to high receiver gain and complexity in band-pass filter of receiver circuit. Alternating light radiation was used to trace fast falling rain drops in wide area. The center wavelength of infrared light source was chosen to $875 \mathrm{~nm}$, which was close to the peak response of silicon photodiode by using $\mathrm{Ga}_{1-x} \mathrm{Al}_{x}$ As emitter with proper composition in III-V ternary compound semiconductor. Also the emission wavelength of light emitter needs to match with transmission spectral range of photodiode with daylight filter to provide additional rejection to sun light. The block diagram of transmitter is shown in Figure 9, and measured transmitter waveform is shown in Figure 10.

Optical interference filter was placed on photodetector window of optical receiver to reject unwanted wavelength and electrical demodulation enhanced signal-to-noise ratio. Recovered response was boosted to the usable signal level for analog-to-digital conversion with enhanced SNR. Block diagram of optical receiver is shown in Figure 11, and measured receiver waveform is shown in Figure 12.

It is needed in automobile to have multiple operating steps by monitoring rain intensity. Rain detection algorithm based on time-to-intensity transformation process is used to have rain data such as rain drop size and rain drop count and further to closely match sensor output to actual raining condition. In Figure 13, the flow chart of the above rain detection algorithm is shown. And actual LCD window viewing the result of rain detection algorithm is shown in Figure 14, as instantaneous rain count is $50 \%$ in one frame time, average rain count is $45 \%$, instantaneous rain drop size is $30 \%$ in one frame time, and average rain drop size is $30 \%$.

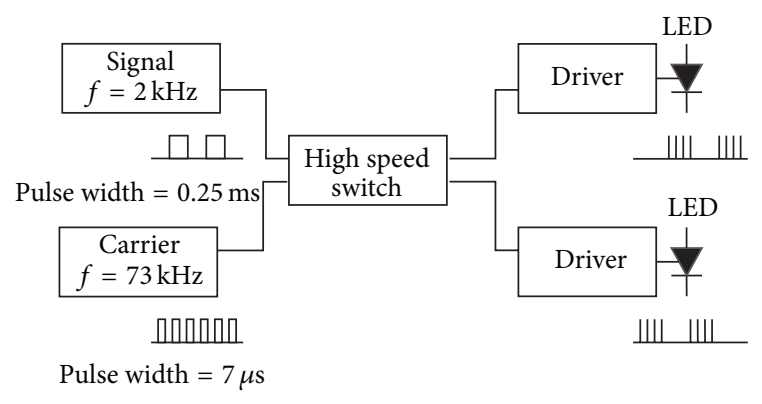

FIGURE 9: Block diagram of transmitter.

Further it shows that wiper starts to operate because preset threshold is $20 \%$.

3.3. Laboratory Measurement. Rain sensor was mounted under windshield glass by using tilt mechanism as shown in Figure 15(a), and this experimental setup was used to monitor maximum sensitivity as mist accumulation on the surface of windshield glass. The output of rain sensor showed sufficient sensitivity to detect mist on glass surface as shown in Figure 16. The shown waveform was modified after converting to digital signal by applying threshold voltage.

Rain sensor was situated inside simulated rain chamber as shown in Figure 15(b), and this experimental setup was used to monitor sensor output against light rain, spraying $400 \mathrm{cc} / \mathrm{min}$, and normal rain, spraying $900 \mathrm{cc} / \mathrm{min}$. The water sprayers inside simulated rain chamber were installed above windshield glass, and two different sizes of nozzle in water sprayer gun were used to simulate lightly raining condition and normal raining condition. The output signal waveform of rain sensor after digitizing and time expansion $(\times 140)$ for control circuitry is demonstrated in Figure 17. The waveform in Figure 17(a) shows the response for light rain, which is equivalent to 45 rounds/min of wiper actuation, and the waveform in Figure 17(b) shows the response for normal rain, which is equivalent to 70 rounds/min of wiper actuation.

Experimental result inside simulated rain chamber showed distinct difference between the cases for light rain and normal rain. For the raining intensity below light rain level, the intermittent wiper actuation was used whenever sensor detected rain drops. In case when averaging function to count raining time slots is used, the sensor response showed tendency of a little weaker response than the case without averaging. In the proposed rain sensor structure, the tilting angle of rain sensor against windshield glass is key parameter to determine sensitivity. Also this angle is subject to adjustment depending on the thickness of windshield glass and distance to windshield glass. The enclosure for rain sensor was securely attached to windshield glass by using adhesive. The entire optical structure of rain sensor was situated close to windshield glass surface within $0.5 \mathrm{~mm}$ clearance inside enclosure. And one end of sensor was fixed to the enclosure by using hinge joint and the other end was tilted by using adjustment bolt with fine thread. The freedom to tilting angle was found to be within 6 degrees 


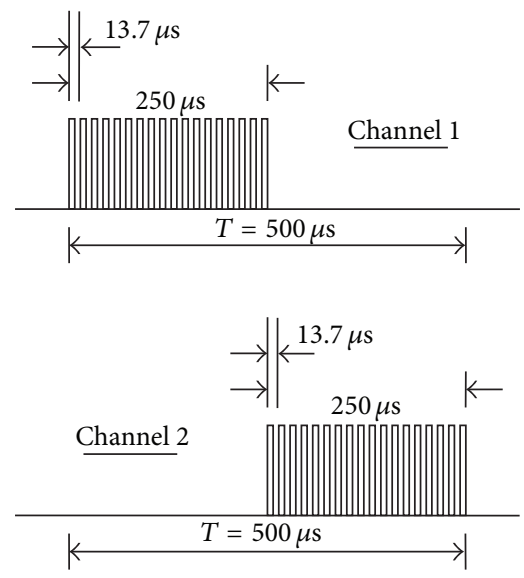

(a)

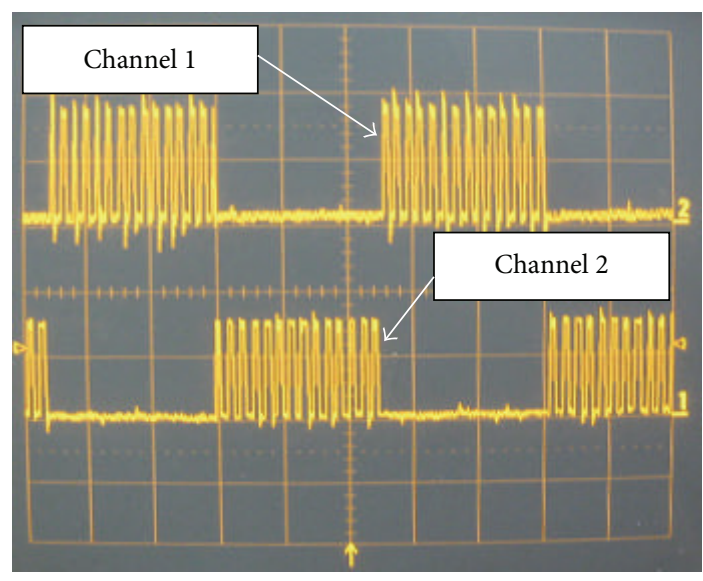

(b)

FIGURE 10: Transmitter signal: (a) signal format and (b) measured waveform, $X=0.1 \mathrm{~ms} / \mathrm{div} Y=2 \mathrm{~V} / \mathrm{div}$.

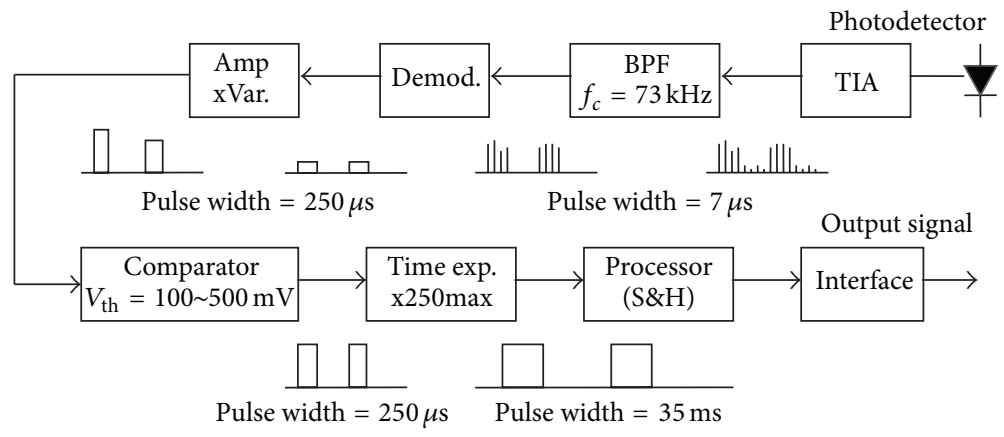

FIGURE 11: Block diagram of receiver.

Light raining

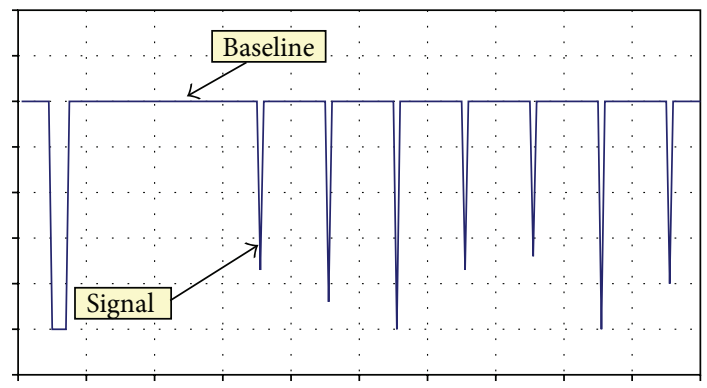

(a)

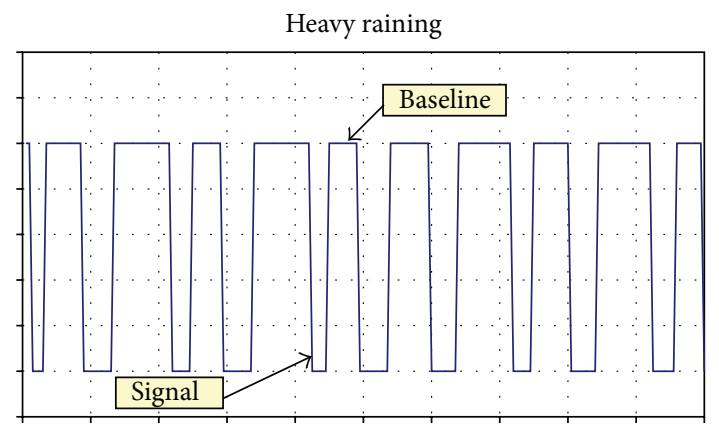

(b)

FiguRE 12: Inverted receiver signal before digital conversion: (a) light raining and (b) heavy raining, $X=0.5 \mathrm{~ms} / \mathrm{div} Y=1 \mathrm{~V} / \mathrm{div}$.

in the experiment. After adjustment, adjustment bolt was fixed by using thread locking compound. However if we try to integrate this rain sensor to the windshield glass of automobile outside laboratory, further consideration for rigid mounting methodology needs to be derived against mechanical displacement due to vibration while driving. Also simple calibration procedure for the specified sensitivity is necessary to suit mass production environment through further research.

\section{Conclusion}

Optoelectronic rain sensor with stacked light waveguide having tilted air gap was investigated towards the application for automotive rain sensor. This open type without optical collimation fixture had the advantage of wide sensing coverage and simple structure, yet having enhanced sensitivity and linearity. Proposed rain sensor detected deflected light path by rain drop on top surface of waveguide glass and scattered 


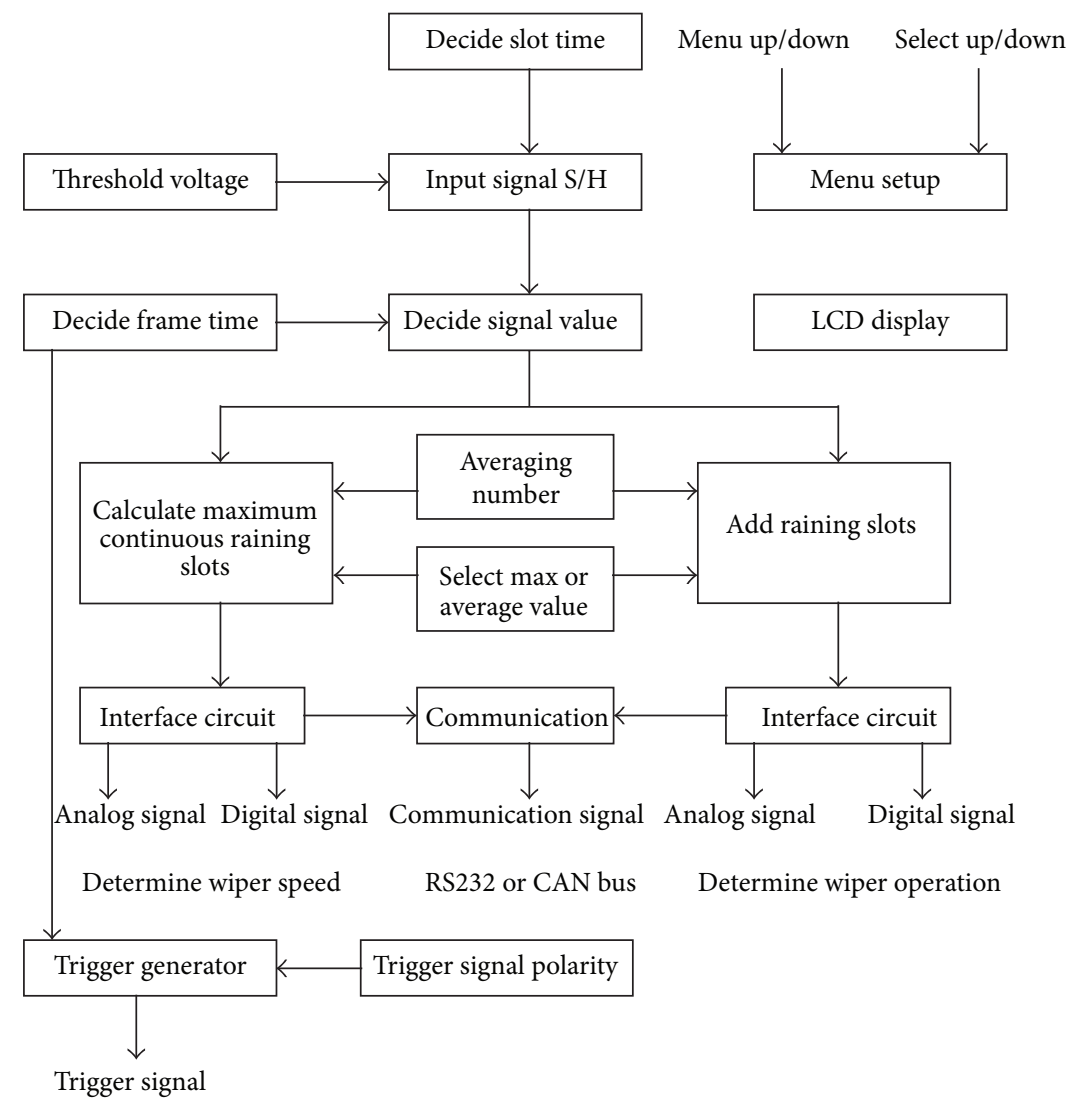

FIGURE 13: Rain detection algorithm.

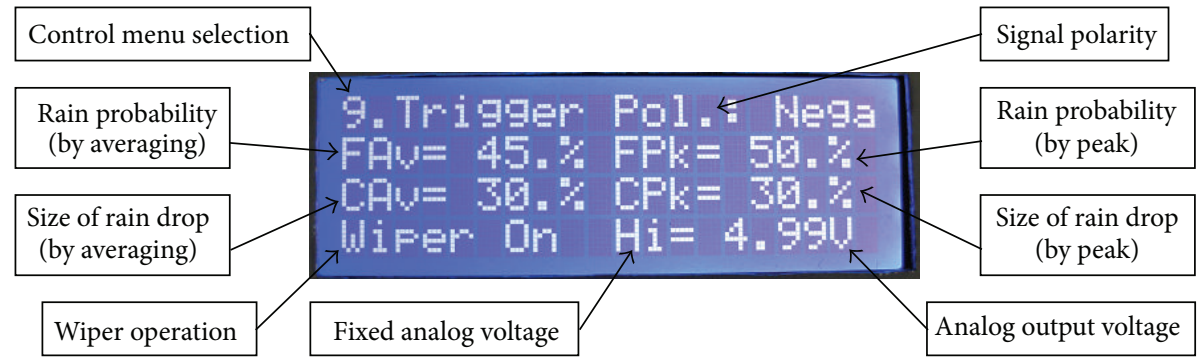

FIGURE 14: LCD window viewing rain detection algorithm.

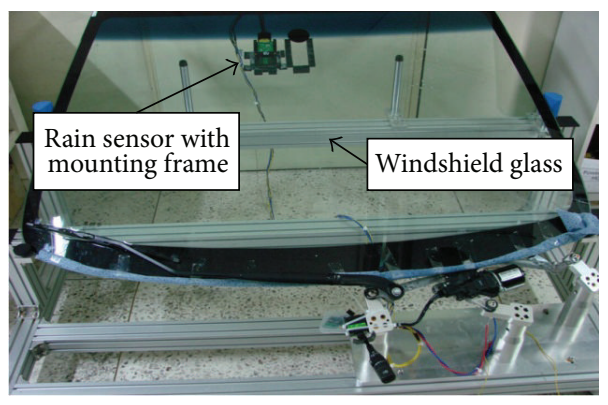

(a)

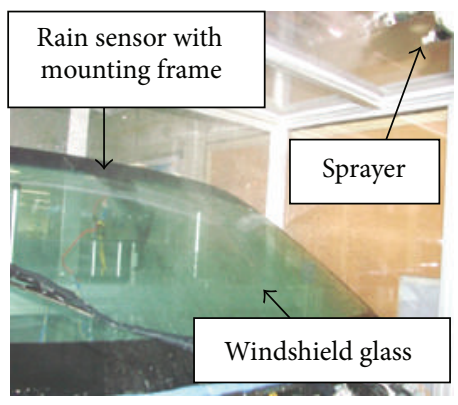

(b)

FIGURE 15: Rain sensor under measurement: (a) mounted on jig and (b) encased in simulated rain chamber. 


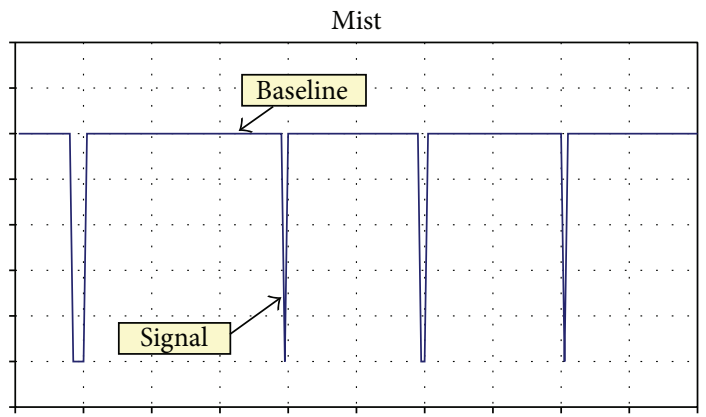

FIGURE 16: Inverted sensor response against mist accumulation on glass surface just after converting to digital signal, $X=0.5 \mathrm{~ms} / \mathrm{div} Y=$ $1 \mathrm{~V} /$ div.

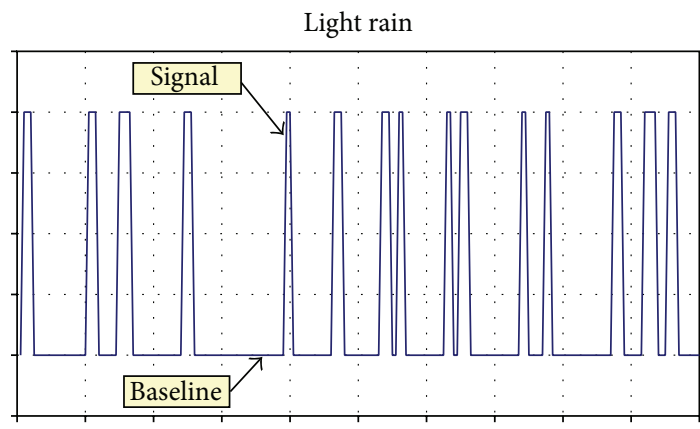

(a)

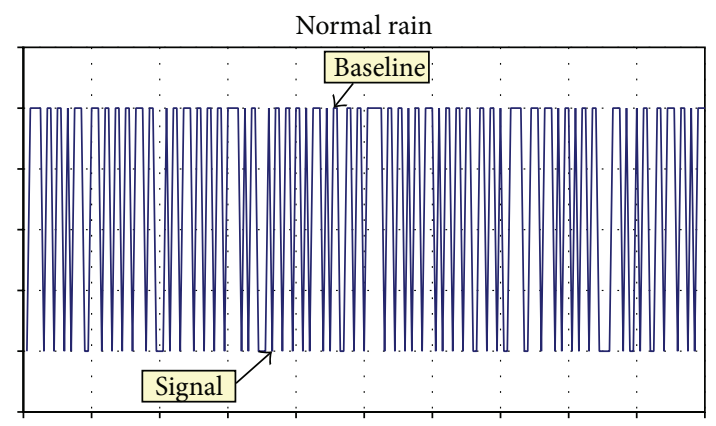

(b)

FIGURE 17: Rain sensor output after digital conversion inside simulated rain chamber: (a) light rain $400 \mathrm{cc} / \mathrm{min}$ and (b) normal rain $900 \mathrm{cc} / \mathrm{min}$, $X=400 \mathrm{~ms} / \operatorname{div} Y=1 \mathrm{~V} /$ div.

light reflection by rain drop above the waveguide glass; thus, it replaced complex guided wave optics in previous rain sensor. The omnidirectional light emitting pattern from light source expanded sensing coverage, and tilting air gap between light blocking fixture and stacked glass waveguide played major role not only to increase sensitivity but also to enhance linearity against raining intensity. The sensing area of rain sensor covers the adjacent area connecting light source and photodetector, which is comparable to guided wave optical sensor having sensitivity only in the line connecting light source and photodetector. Adequate signal-to-noise ratio was maintained by using optical interference filter and electrical signal modulation to have noise rejection capability, while keeping high signal amplification rate. Detection algorithm based on time-to-intensity transformation process was used to convert raining intensity into countable raining process by using time division detection slots. Rain sensor mounted on laboratory jig showed high sensitivity to detect mist accumulation on the surface of windshield glass. Experimental result, which was measured inside simulated raining chamber, showed distinct difference between the cases for light rain, spraying $400 \mathrm{cc} / \mathrm{min}$, and normal rain, spraying $900 \mathrm{cc} / \mathrm{min}$. This test result using simulated rain chamber indicated prospect as rain sensor for automotive application. However, natural raining condition is random; thus, the test result outside laboratory may differ from the result inside laboratory using water spray guns. In this case, extended experiment in outside raining environment will be helpful to optimize.

\section{Conflict of Interests}

The author declares that there is no conflict of interests regarding the publication of this paper.

\section{Acknowledgment}

This work was supported by Incheon National University Research Grant in 2013.

\section{References}

[1] K. Kobayashi, M. Kato, K. Fujisawa, Y. Nagamine, and F. Nakajima, "Rain sensor in an automatic wiper drive control system for an automotive vehicle," US Patent 4,584,508, 1986.

[2] E. M. Trono, M. L. Guico, N. J. C. Libatique et al., "Rainfall monitoring using acoustic sensors," in Proceedings of the IEEE Region 10 Conference: Sustainable Development Through Humanitarian Technology (TENCON '12), Cebu, Philippine, November 2012.

[3] M. Joshi, K. Jogalekar, D. N. Sonawane, V. Sagare, and M. A. Joshi, "A novel and cost effective resistive rain sensor for automatic wiper control: Circuit modelling and implementation," in 
Proceedings of the 7th IEEE International Conference on Sensing Technology (ICST '13), pp. 40-45, Wellington, New Zealand, December 2013.

[4] S. A. VanDam, "Windshield wiper rain sensor system," US Patent 5,780,719, July 1998.

[5] K. O. West, "Rain sensor car electric window closure control," US Patent 5,293,105, March 1994.

[6] H. J. Schroder, "Rain sensor," US Patent 5,659,294, August 1997.

[7] H. J. Schroder, "Rain sensor," US Patent 5,598,146, 1997.

[8] M. Jarajreh, A. L. Nortcliffe, and R. Green, "Fuzzy logic and equivalent circuit approach to rain measurement," Electronics Letters, vol. 40, no. 24, pp. 1533-1534, 2004.

[9] V. S. Veerasamy, "Rain sensor with fractal capacitor," US Patent 8,009,053B2, August 2011.

[10] V. S. Veerasamy, "Rain sensor with capacitor-inclusive circuit," US Patent 7,561,055B2, 2009.

[11] Y. Netzer, "Differential windshield capacitive rain sensor," US Patent 6,373,263B1, 2002.

[12] P. A. Hochstein, "Capacitive rain sensor for windshield," US Patent 6,094,981, 2000.

[13] J. J. Buschur, "Windshield rain sensor," US Patent 5,668,478, September 1997.

[14] D. L. Mueller and G. A. Nyberg, "Vehicle windshield and wiper with rain sensor," US Patent 4,827,198, 1989.

[15] P. A. Hochstein, "Rain sensor," US Patent 4,703,237, October 1987.

[16] K. K. Koram, A. R. Hawk, and S. Chun, "Windshield moisture detector," US Patent 7,204,130B2, 2007.

[17] N. R. Lynam, "Rain sensor with fog discrimination," US Patent 6,353,392B1, May 2002.

[18] P. A. Hochstein, "Off the glass imaging rain sensor," US Patent 6,207,967B1, 2001.

[19] G. Reime, "Rain sensor device for detecting the wettind and/or soiling of a windscreen surface," US Patent 7,259,367B2, August 2007.

[20] P. A. Hochstein, “Differential imaging rain sensor," US Patent 6,603,137B2, 2003.

[21] P. A. Hochstein, "Interleaved mosaic imaging rain sensor," US Patent 6,573,490B2, 2003.

[22] P. A. Hochstein, "Stereo imaging rain sensor," US Patent 6,596,978B2, 2003.

[23] N. R. Lynam, B. J. Bos, K. Schofield, and M. L. Larson, "Rain sensor," US Patent 6,313,454B1, 2001.

[24] K. Schofield, M. L. Larson, and K. J. Vadas, "Vehicle rain sensor using imaging sensor," US Patent 6,320,176B1, 2001.

[25] S. Görmer, A. Kummert, S. Park, and P. Egbert, "Vision-based rain sensing with an in-vehicle camera," in Proceedings of the IEEE Intelligent Vehicles Symposium, pp. 279-284, Xi'an, China, June 2009.

[26] T. Tsukamoto, "Rain sensor," US Patent 7,646,889B2, January 2010.

[27] J. Booth, "Weather and radar interactions," in Proceedings of the IEEE Aerospace Conference, pp. 1202-1212, Big Sky, Mont, USA, March 2005.

[28] M. Kemp, A. Kruger, and J. Niemeier, "Design considerations and signal processing for a microwave rain gauge sensor," in Proceedings of the IEEE International Conference on Electro/Information Technology (EIT '12), pp. 1-4, May 2012.

[29] B. Schmid, "Rain sensor with bonded chips," US Patent 6,526,820B1, March 2003.
[30] G. Reime, " Rain sensor using low harmonic content signals," US Patent 6,634,225B1, 2003.

[31] T. Taoka, "Rain sensor," US Patent 8,362,453B2, 2013.

[32] S. Y. Han, “Rain sensor," US Patent 8,471,513B2, June 2013.

[33] P. A. Hochstein, "Rain sensor with reference channel," US Patent 4,960,996, 1990.

[34] H. Sautter, "Rain sensor with light-conducting body for a motor vehicle," US Patent 6,810,729B2, 2004.

[35] R. S. Teder, "Multi-mode rain sensor," US Patent 7,847,255B2, 2010.

[36] S. Tanaka, “Transparent substrate having rain sensor," US Patent 5,991,049, November 1999.

[37] K. H. Wohlfahrt, "Rain sensor," US Patent 7,911,356B2, March 2011.

[38] N. R. Lynam, "Rain sensor mounting system," US Patent 6,968,736B2, 2005.

[39] G. Michenfelder, G. Riehl, M. Burkart, and K. Roth, "Rain sensor," US Patent 7,236,249B1, 2007.

[40] K. N. Choi, "Omni-directional rain sensor utilizing scattered light reflection by water particle on automotive windshield glass," in Proceedings of the 10th IEEE SENSORS Conference (SENSORS '11), pp. 1728-1731, October 2011.

[41] H. C. van de Hulst, Light Scattering by Small Particles, Academic Press, New York, NY, USA, 1981.

[42] J. A. Stratton, Electromagnetic Theory, McGraw Hill, New York, NY, USA, 1941.

[43] P. W. Barber and S. C. Hill, Light Scattering by Particles; Computational Methods, World Scientific, Singapore, 1990.

[44] M. I. Mishchenko, J. W. Hovenier, and L. D. Travis, Light Scattering by Non-Spherical Particles: Theory, Measurements, and Applications, Academic Press, San Diego, Calif, USA, 2000. 

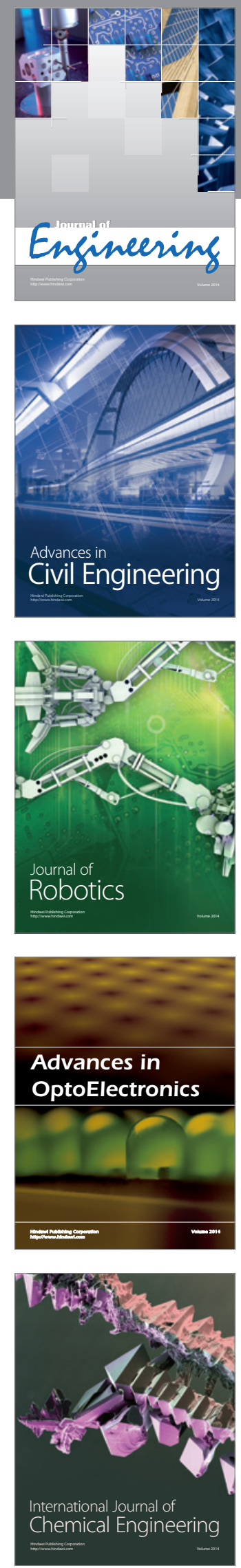

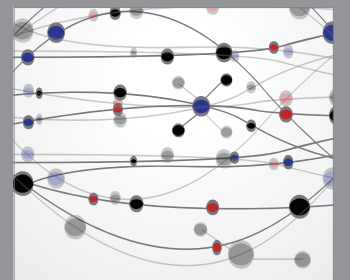

The Scientific World Journal
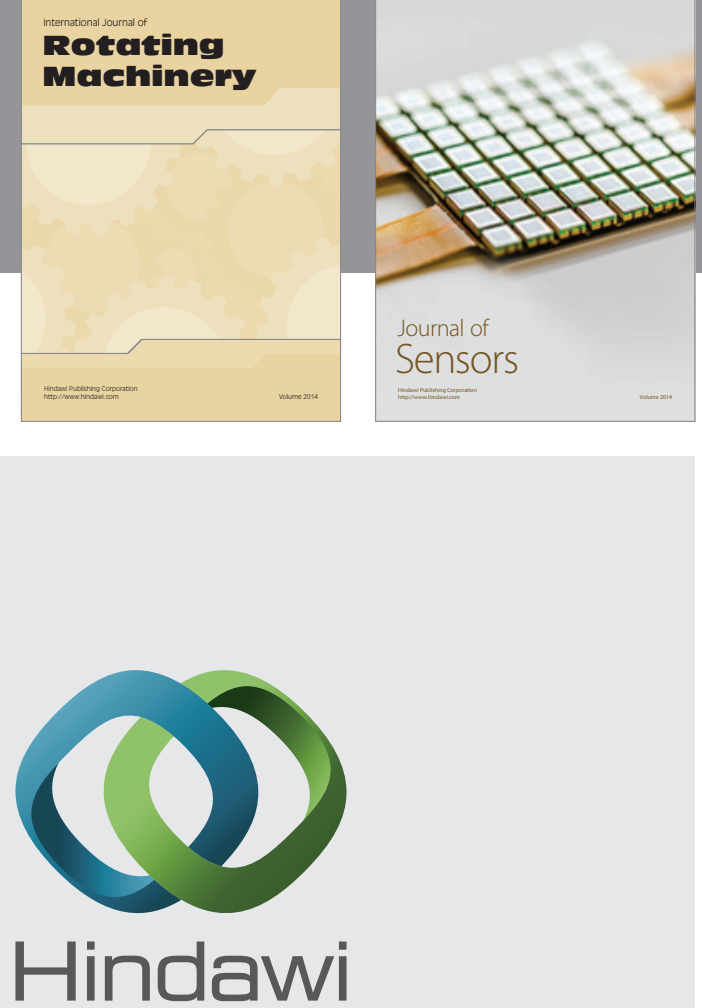

Submit your manuscripts at http://www.hindawi.com
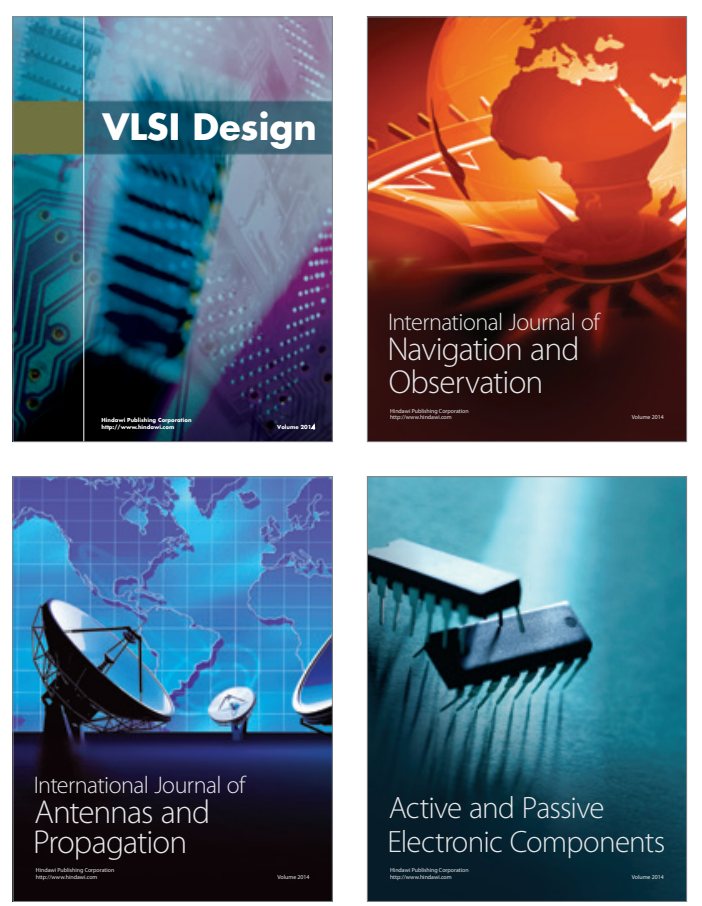
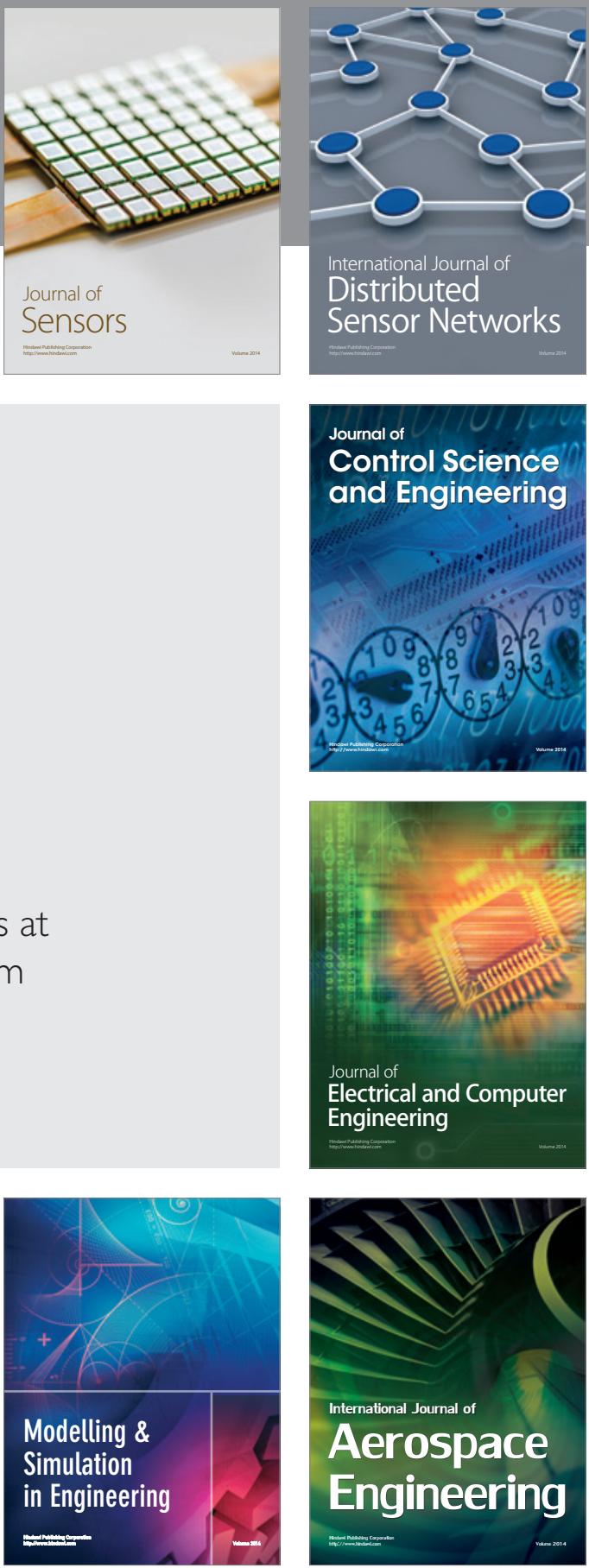

Journal of

Control Science

and Engineering
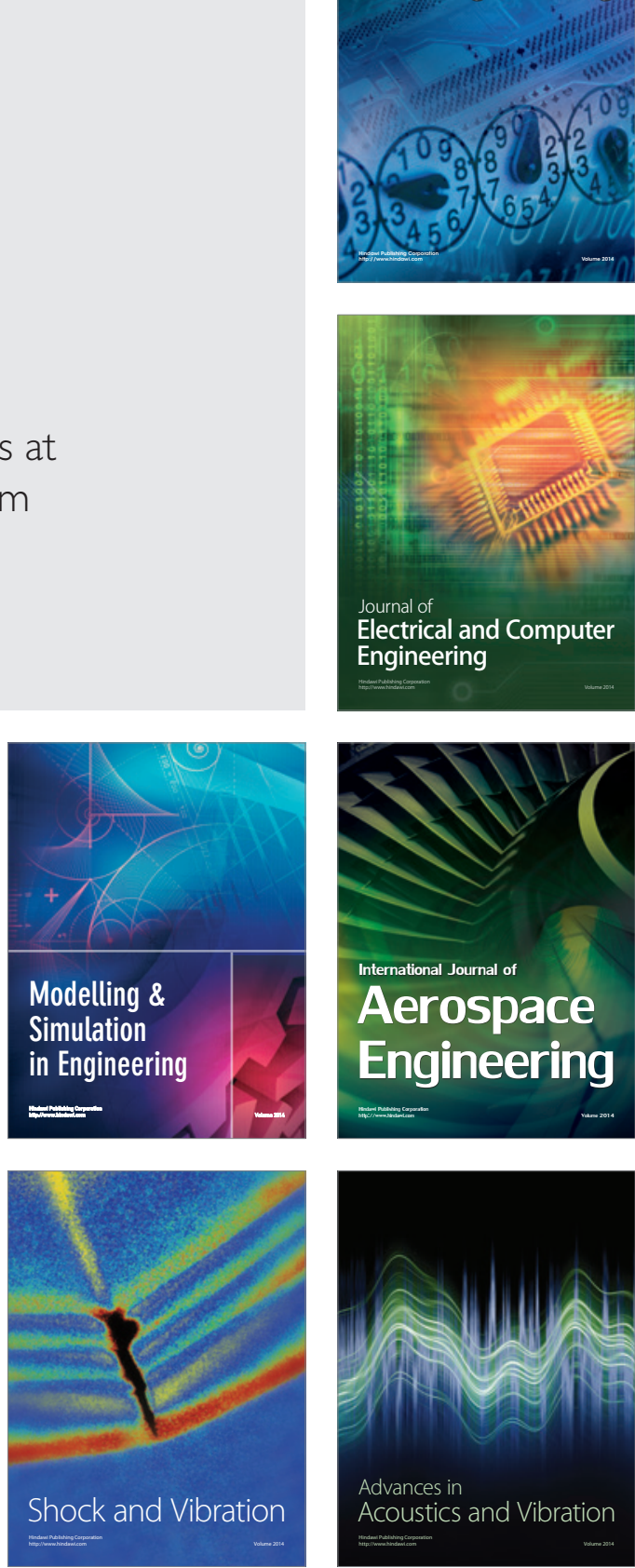